\title{
The Impact of Teaching Instructional and Environmental Strategies on Iranian EFL Young Learner's Grammar Achievement
}

\author{
Negar Sadeghi Hariri (Corresponding author) \\ Department of TEFL Faculty of Literature and Foreign Languages, Islamic Azad University, Qazvin Branch, Qazvin, Iran \\ E-mail: negari86@yahoo.com \\ Natasha Pourdana \\ Faculty of Literature and Foreign Languages, ELT Department of Higher Education, Islamic Azad University, Karaj Branch, Karaj, Iran
}

Received: 07-08-2016

Accepted: 04-10-2016

Published: 10-12-2016 doi:10.7575/aiac.ijalel.v.5n.7p.77
Advance Access Published: November 2016

URL: http://dx.doi.org/10.7575/aiac.ijalel.v.5n.7p.77

\begin{abstract}
The present study attempted to investigate the possible effects of Instructional (INS) and Environmental (ENS) strategies on Iranian EFL young learners' grammar achievement. For this purpose, 82 female language young learners ranged between 8 to 12 years of age were selected and randomly assigned into INS, ENS and Control groups in this study. After taking EPT, INS and ENS groups received EFL grammar structures accompanied by INS and ENS strategies, respectively, while Control group received only conventional instructions to English grammar. After conducting the treatment, all participants took a grammar post-test. The Null hypotheses 1 and 2 in this study assumed that the INS and the ENS strategies had no impact on Iranian EFL young learners' grammar achievement. They were successfully rejected due to different performance of INS and ENS groups from Control group on the post-test. Statistical results did support the superiority of INS over ENS strategies. Therefore, the researcher was able to rectify that INS strategies caused higher impact on the young learners' grammar achievement than ENS strategies. She concluded her work with some pedagogical implications and recommended topics for further research.
\end{abstract}

Key words: Bulletin boards, Cooperate Learning, Environmental Strategy, Grammar Achievement, Instructional Strategy, Young Learners

\section{Introduction}

Grammar in English as a Foreign Language situation was an early obstacle to overcome for a long time. More importantly, it was considered a vital issue in Foreign Language context too. The process of learning grammar however was different among FL learners.

As Skehart (1989), Larsen-Freeman and Long (1991), Ellis (1994), stated learning grammar was totally different among learners in the EFL situation. As it goes, a lot of interest has been growing among EFL teachers and researchers in the young learner's learning foreign language (Hui, 2013).

Despite unattractiveness and mostly unpleasant phase in classroom, many EFL teachers have tried to make grammar teaching imaginative moments for the EFL students. Previous studies have emphasized disparity between students and teachers. While EFL students were interested in error correction, EFL teachers did agree on communicative activities (Brindley, 1984; Kumaravadivelu, 1991; Leki, 1995; Schultz, 2001).

Studies confirm that complete removal of native language in foreign language classrooms is not appropriate. Freeman (1991), Nation (2003), Schweers, (1999). They emphasize that when the mother tongue used appropriately, the use of L1 can be very beneficial.Brown (2000) claims that "First language can be a fascinating factor and not just interfering factor". Schweers (1999) calls teachers to integrate the mother tongue into lessons to influence the classroom dynamic, and suggests, "Starting with L1 provides a sense of security and validates the learner's lived experiences, allowing them to express themselves". Much research has been published in the field of teaching foreign language by using monolingual approach in ESL teaching.

According to Verghese (1989) "A knowledge of grammar is perhaps more important to a second language learners than to a native speaker". Because of the procedure of acquiring the language is different; the native speaker has creatively internalized the grammar of the language while the second language learner has to make a conscious effort to master those aspects and parts of the language grammar.

EFL Students' expectations have favored by many EFL teachers, as Burgess and Etherington (2002, p.440-441) stated that students favor explicit teaching just for the sake of security.The study indicated that EFL teachers mostly favored communicative activities whereas EFL students found it difficult to develop grammatical knowledge. Moreover, throughout communicative activities, EFL students have not acquired complete grammatical knowledge. 
Instructional strategies included all approaches that an EFL teacher might take to engage EFL students in learning. These strategies drove an EFL teacher's instructions to meet specific objectives and helped EFL students to be more independent to use effective strategies to accomplish their specific goals. In other words, it would motivate EFL students to have a better understanding and remembering. In order to make successful EFL learners, EFL students needed to follow strategies step by step and tried to make a connection between skills, and real life (Alberta, 2011).

Instructional strategies could have an extreme effect on educational programs. As Marzano (2009) presented nine highly yielded instructional strategies to facilitate learning process.

1. Identifying similarities and differences

2. Summarizing and note taking

3. Reinforcing effort and providing recognition

4. Providing homework and practice

5. Representing nonlinguistic features

6. Learning cooperatively

7. Setting objectives and providing feedback

8. Generating and testing hypothesis

9. Presenting questions, cues, and advance organizers

According to Marzano (1998),who summarized over 100 researches to design the above mentioned categories. The first category included comparing, classifying, creating metaphors and creating analogies. In order to help EFL students identifying similarities and differences, three different tasks were presented to them: teacher-directed tasks, studentdirected tasks and graphic organizers. Teacher-directed tasks were useful to help EFL students to gain specific information for completing the task whereas student-directed tasks required less guidance and graphic organizers have given EFL students better understanding and visualizing at the same time (Marzano, Gaddy \& Dean, 2000).

Summarizing and note taking belonged to the same category which required EFL students' effort to analyze the information which was vital for making notes. In order to achieve the specific goal, EFL students were asked to make their notes as brief as possible to acquire the effects of note taking (Crooks, Powlie \& Tripp, 1984).

Unlike reinforcing effort and providing recognition which dealt with EFL students' engagement, homework and practice gave EFL students an opportunity to learn practice skills. Nonlinguistic representations were the next important category which required kinesthetic activities and using pictures and pictographs. EFL teachers were going to teach EFL learners special skills to use pictures and graphs for better understanding. Next following categories except the last one focused on the importance of cooperation and EFL student's engagements. Final category has brought EFL student's prior knowledge to the field of the study to retrieve what they already know about topics and they were presented the advance organizers to learn how to use this background knowledge (Dean, Gaddy \& Marzano, 2000).

Majority of Asian countries have treated English as a foreign language which was the subject to be studied rather than a living language. Moreover, "The lack of a surrounding community of English speakers outside the classroom has increased the challenge for EFL instructors immensely" (Wu\& Wu, 2008, p.212). As Parker, Babbs and Cohen (1995) suggested the opportunity for communication in authentic situations and settings, especially with native speakers, was a major factor for second-language acquisition by adults ( $\mathrm{Wu} \& \mathrm{Wu}, 2008$, p. 212).

As $\mathrm{Wu}$ and $\mathrm{Wu}$ (2008) believed in several ways to improve practicing, the main focus was given to cooperative learning, such as scaffolding and students-students interaction. However the impact of non-academic location such as department stores, churches and restaurants could increase the availability of native English language speakers.

Long before, Bejarano (1987) pointed out different cooperative techniques for 665 pupils in seventh grade classes for cooperative learning. The DG (Discussion Group) technique which required group participation, peer ideas, sharing information demanded a great deal of EFL teachers' facilitation to reach the specific goals. Unlike the difficulties, the findings supported the link between communicative approach and cooperative learning in small groups. The technique demonstrated the great result which EFL students were more motivated with a significant involvement in meaningful communication in comparison with the whole-class involvement.

A good example of meaningful communication was an Environmental education which was applied for many purposes. Lucas (1972) presented environmental education to facilitate learning and considered this as an umbrella term which incorporated different strategies from natural science to social science. Besides, it could help EFL learners for social learning and Adaptive management (Andrews, Beidenweg \& Monore, 2007).

Then after, Wells (2007) claimed a teaching strategy which was used for adults through the use of "Bulletin Boards". Bulletin boards were visual displays which provided information through pictures and words for all ages (Rains \& Williamson, 2012). In order to create Bulletin Boards, different factors had to take into account such as, font style and size, color, lightening, pictures.

\section{Method}

The participants in this study were 82 Iranian female EFL learners at the basic level of English proficiency, studying at Simin Language School in Karaj during the summer semester, 2015. They were between 8 to 12 years of age. The 
researcher used three intact groups as the participants in this study. Each group attended fifteen-session English classes. They were provided EPT as a pre-test and their final examination as a post-test.

Group 1: Those who received English grammars through Instructional strategy. (INS Group, n=35)

Group 2:Those who received English grammars through Environmental strategy. (ENS Group, n=25)

Group 3:Those who received English grammars followed by a number of comprehension questions in post-grammar phase. (Control group, $\mathrm{n}=22$ )

\section{Result and Discussion}

The data collected for three groups of INS, ENS and Control groups on the Pre and Post tests are descriptively analyzed and tabulated in Table 1.

Table 1. Descriptive Statistics for INS, ENS and Control Groups

\begin{tabular}{|c|c|c|c|c|c|c|c|c|c|}
\hline & \multirow{2}{*}{$\begin{array}{c}\mathrm{N} \\
\text { Statistic }\end{array}$} & \multirow{2}{*}{$\begin{array}{c}\text { Minimu } \\
\text { m }\end{array}$} & \multirow{2}{*}{$\begin{array}{c}\text { Maximu } \\
\text { m } \\
\text { Statistic }\end{array}$} & \multirow{2}{*}{$\begin{array}{c}\text { Mean } \\
\text { Statistic }\end{array}$} & \multirow{2}{*}{$\begin{array}{c}\text { Std. } \\
\text { Deviation } \\
\text { Statistic }\end{array}$} & \multicolumn{2}{|c|}{ Skewness } & \multicolumn{2}{|c|}{ Kurtosis } \\
\hline & & & & & & Statistic & $\begin{array}{l}\text { Std. } \\
\text { Error }\end{array}$ & Statistic & $\begin{array}{l}\text { Std. } \\
\text { Error }\end{array}$ \\
\hline INSPre & 34 & 14.00 & 20.00 & 17.8971 & 1.68676 & -.244 & .403 & -.857 & .788 \\
\hline INSPost & 34 & 18.00 & 20.00 & 19.7059 & 49417 & -1.941 & .403 & 3.719 & .788 \\
\hline ENSPre & 22 & 16.00 & 20.00 & 18.3409 & 1.53053 & -.293 & .491 & -1.622 & .953 \\
\hline ENSPost & 22 & 14.50 & 20.00 & 18.2727 & 1.75748 & -1.284 & .491 & .411 & .953 \\
\hline ConPre & 18 & 15.00 & 20.00 & 19.0833 & 1.30891 & -1.953 & .536 & 4.667 & 1.038 \\
\hline ConPost & 18 & 13.50 & 19.50 & 17.4444 & 1.89340 & -.642 & .536 & -.823 & 1.038 \\
\hline $\begin{array}{c}\text { Valid N } \\
\text { (listwise) }\end{array}$ & 18 & & & & & & & & \\
\hline
\end{tabular}

As Table1demonstrates, the size of the groups in this study was various in three groups $\left(\mathrm{N}_{\text {INS }}=34, \mathrm{~N}_{\mathrm{ENS}}=22, \mathrm{~N}_{\text {Control}}=18\right)$. In the performance of INS, ENS and Control groups on Pre-test and Post-test in this study, the scores have ranged from 14.00 to 20.00, with the broadest range belonging to Control Group (13.50 to 20.00).

Regarding mean scores, a considerable improvement is seen for the INS group from Pre to Post test $\left(\overline{\mathrm{X}}_{\mathrm{INSPre}}=17.89\right.$, $\left.\overline{\mathrm{X}}_{\text {INSPost }}=19.70\right)$. The mean scores for the ENS group remained rather stable from Pre to Post test $\left(\overline{\mathrm{X}}_{\mathrm{ENSPre}}=18.34\right.$, $\left.\overline{\mathrm{X}}_{\text {ENSPost }}=18.27\right)$. Finally, the mean scores for the Control group show a considerable decrease from Pre to Post test $\left(\overline{\mathrm{X}}_{\text {ConPre }}=19.08, \overline{\mathrm{X}}_{\text {ConPost }}=17.44\right)$.

To graphically compare the performance of the groups on Pre and Post-tests, an assembly of boxplots were created in Figure1.

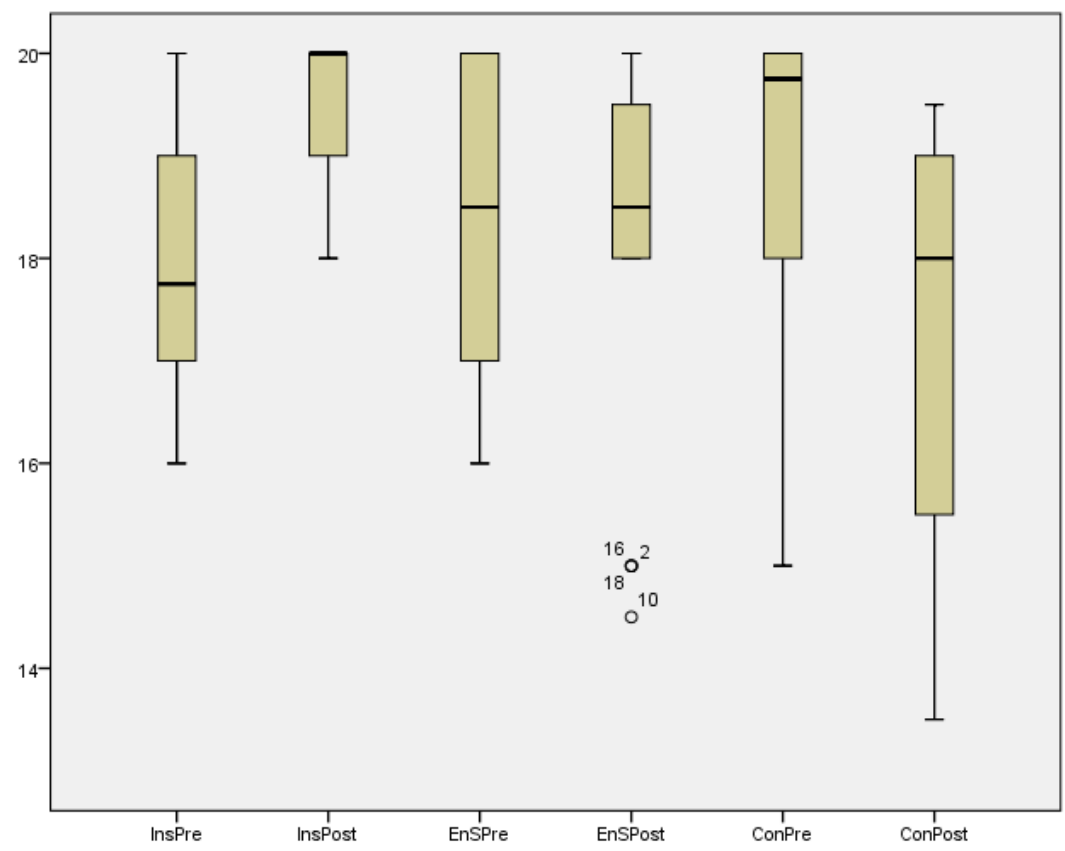

Figure 1. Boxplots for INS, ENS and Control groups' performance on Pre and Post Tests 
Figure1 demonstrates the relative homogeneity of variances in the 6 sets of scores in this study. At the first glance, the negative skewness and asymmetrical performance of all groups on Pre and Post tests show up. The shrink of the hinges for INS and ENS groups from Pre to Post-test show a similarity of performance on Pre and Post-tests with an improved homogeneity on Post-test. A number of outliers in ENS group is the point of departure between the two groups. On the other side, the Control group has moved from a more symmetrical performance on Pre-test to a weaker performance and more heterogeneity on Post-test. To Compare the normality of INS, ENS and Control groups on Pre-test and Post-test, a normality test of Kruskal-Wallis was run.

Table 2 (a, b). Mean Ranking and Normality of INS, ENS and Control groups on Pre Test

\begin{tabular}{llll}
\multicolumn{2}{l}{ Ranks } & \multicolumn{3}{l}{} \\
\hline \multirow{2}{*}{ Pre } & Group & $\mathrm{N}$ & Mean Rank \\
\cline { 2 - 4 } & InsGroup & 34 & 33.35 \\
\cline { 2 - 4 } & EnsGroup & 23 & 44.37 \\
\cline { 2 - 4 } & ConGroup & 17 & 36.50 \\
\cline { 2 - 4 } & Total & 74 & \\
\hline
\end{tabular}

\begin{tabular}{ll}
\multicolumn{2}{l}{ Test Statistics $^{\mathrm{a}, \mathrm{b}}$} \\
\hline & Pre \\
\hline Chi-Square & 4.477 \\
\hline df & 2 \\
\hline Asymp. Sig. & .107 \\
\hline a. Kruskal Wallis & Test \\
\hline b. Grouping Variable: Group
\end{tabular}

As Table 2(a) demonstrates, the ENS group with the highest mean is ranked as the first performance on Pre-test $\left(\bar{X}_{\text {Rank }}=33.35\right)$, the Control group, the second $\left(\bar{X}_{\text {Rank }}=36.50\right)$ and the INS group, the third $\left(\bar{X}_{\text {Rank }}=33.35\right)$. In Table 2(b), the measure of Chi-Square $\left(\chi^{2}=4.477, \mathrm{p}\right.$-value= 107$)$ shows an insignificant difference among the groups. Therefore, the assumption of normality is not violated in the scores of INS, ENS and Control groups on Pre-test. The same analysis was done with the INS, ENS and Control Groups' scores on Post-test.

Table $3(\mathrm{a}, \mathrm{b})$

\begin{tabular}{llll}
\hline Group & & $\mathrm{N}$ & Mean Rank \\
\hline Post & InsGroup & 34 & 49.46 \\
\cline { 2 - 4 } & EnsGroup & 23 & 30.52 \\
\cline { 2 - 4 } & ConGroup & 17 & 23.03 \\
\cline { 2 - 4 } & Total & 74 & \\
\cline { 2 - 3 } & &
\end{tabular}

(a) Mean Ranking and Normality of INS, ENS and Control groups on Post Test

\begin{tabular}{ll}
\multicolumn{2}{l}{ Test Statistics } \\
& Post \\
\hline Chi-Square & 22.302 \\
\hline df & 2 \\
\hline Asymp. Sig. & .000 \\
\hline a. Kruskal Wallis Test \\
\hline \multicolumn{2}{l}{ b. Grouping Variable: Group }
\end{tabular}

As Table 3 (a) displays, the INS group with the highest mean is ranked as the first performance on Post-test $\left(\bar{X}_{\text {Rank }}=49.46\right)$, the ENS group, the second $\left(\bar{X}_{\text {Rank }}=30.52\right)$ and the Control group, the third $\left(\bar{X}_{\text {Rank }}=23.03\right)$. In Table 2(b), the measure of Chi-Square $\left(\chi^{2}=22.302, \mathrm{p}\right.$-value=.000) shows a significant difference among the groups. Therefore, the assumption of normality is violated in the scores of INS, ENS and Control groups on Post-test which led the researcher to run a test of ANOVA to measure the size of this meaningful difference among the groups' performance on Post-test later by means of a test of ANOVA. At the next step, the two null hypotheses in this study are statistically testified.

The Null Hypothesis 1 and 2 in this study, assumed no meaningful effect of either Instructional Strategy (INS) or Environmental Strategy (ENS) on EFL young learners' grammar achievement. The descriptive statistics demonstrated a meaningful difference among the performance of the three groups in favor of INS strategy in this study.

Table 4. One Way ANOVA for INS, ENS and Control groups on Post test

\begin{tabular}{llllll}
\hline & Sum of Squares & df & Mean Square & F & Sig. \\
\hline Between Groups & 26.961 & 2 & 13.481 & 9.913 & .000 \\
\hline Within Groups & 96.552 & 71 & 1.360 & & \\
\hline Total & 123.514 & 73 & & &
\end{tabular}

As Table 4 shows, the index of $F=9.913, \mathrm{df}=2$, is significant at the $\mathrm{p}$-value $=.000$ for the INS, ENS and Control groups' performance on Post-test. To measure the effect size, Measures of Association (Eta Squared) was calculated.

Table 5. Measures of Association

\begin{tabular}{lllll}
\hline & & & Eta & Eta Squared \\
\hline Post & $*$ & INS- & .441 & .195 \\
ENS & & & & \\
\hline
\end{tabular}


To interpret the measure of Eta Squared in Table 5, a reference is made to Pierce et al (2004). Accordingly, Eta ${ }^{2}=.195$ is considered as a small effect size. It can be concluded that the difference in the performance of the INS and ENS groups on Post-test is significant but not very considerable. To further investigate the INS, ENS and Control groups performance on Post-test, a LSD post-hoc test was run.

Table 6. Multiple Comparison among INS, ENS and Control groups on Post test

\begin{tabular}{ccccccc} 
(I) Group & (J) Group & $\begin{array}{c}\text { Mean Difference } \\
(\mathrm{I}-\mathrm{J})\end{array}$ & Std. Error & Sig. & \multicolumn{2}{c}{$95 \%$ Confidence Interval } \\
\cline { 4 - 7 } InsGroup & & & & & Lower Bound & Upper Bound \\
\cline { 2 - 7 } & EnsGroup & $.94501^{*}$ & .31484 & .004 & .3172 & 1.5728 \\
\hline \multirow{2}{*}{ EnsGroup } & ConGroup & $1.44118^{*}$ & .34640 & .000 & .7505 & 2.1319 \\
\cline { 2 - 7 } & InsGroup & $-.94501^{*}$ & .31484 & .004 & -1.5728 & -.3172 \\
\hline ConGroup & .49616 & .37299 & .008 & -.2476 & 1.2399 \\
\cline { 2 - 7 } & InsGroup & $-1.44118^{*}$ & .34640 & .000 & -2.1319 & -.7505 \\
\hline & EnsGroup & -.49616 & .37299 & .008 & -1.2399 & .2476 \\
\hline
\end{tabular}

*. The mean difference is significant at the 0.05 level.

As Table 6 demonstrates, the three groups have performed significantly different from one another. The statistical comparison between INS and ENS groups shows the mean differences (I-J) is .945 which is significant at p-value $=.004$. The INS and Control groups performed differently with a mean difference of 1.441 , significant at $\mathrm{p}$-value $=.000$, too. Similarly, the performance of ENS and Control groups shows a mean difference of .494, significant at p-value $=.008$. These significant differences and the better effect of INS over ENS strategies are graphically demonstrated with means plots.

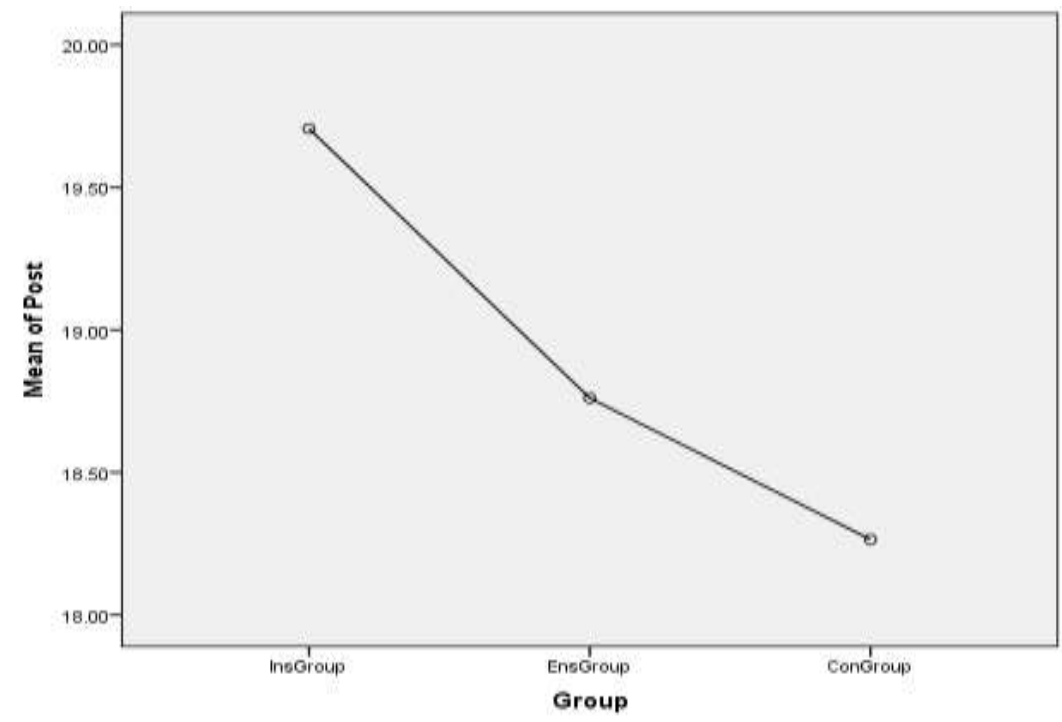

Figure 2. Means Plots for INS, ENS and Control groups' performance on Post Test

The finding in this study is subject to speculation as the size of the Environmental group (ENS) was much smaller than the Instructional, therefore the conclusion is drown cautiously thus the researcher's explanation for the obtained results was indisputable in the sense that the INS strategy has significant effect on grammar achievement. One possible cause for the positive impact of INS strategy on EFL learners' grammar achievement is that applying INS strategy especially non-linguistic representation results in deeper thinking and better understanding. The study in San Diego in Charter school demonstrates that INS strategies like photographs, political cartoons, graphic organizers, provide EFL students with the chance to illustrate understanding and create mental images without being concerned about grammar, spelling and their English proficiency (Rosenzwelg, 2010-2015).Moreover, Nonlinguistic representation of new information have priorities over Environmental strategies. In the hundreds of action research projects that were conducted by EFL teachers throughout the years, specifically across 129 studies in which EFL teachers used nonlinguistic strategies such as graphic organizers, sketches, and pictographs the average effect was 17 percentile point gain in EFL student achievement (Haystead \& Marzano, 2009). Besides, it can reflect individual thinking, improves memory, facilitate creativity and increase retention (Marzano, 2009).

On the other hand the study by Hill and Bjork and Mccrel and Denver (2013) illustrates the same result. The study worked on ELL students on 6 levels with students up to 7 years. The result revealed that non-linguistic representation could help ELL students to enhance their understanding. Besides, it would increase academic language and enable EFL students to talk about their choices and it could consider as a tool for language development.

Rejected Null Hypothesis 2 supports the fact that Environmental strategy (ENS) does have significant impacts on the participants' grammar achievement improvement. The study in 2013 by Anthony Graham in north Chrolina has proven 
the effectiveness of using bulletin boards on EFL students' improvement. In this study, bulletin board was located in the front of the classroom where everyone was able to see that completely and the materials were changed weekly according to the topics. Students were young and worked collaboratively and were able to see and participate in the class activities. The result presented the effect of using bulletin boards on EFL student's achievements and benefited their progress (Graham, 2013).

Similarly, in 2002 a teacher of fourth grade used bulletin boards in order to enhance writing process in students. The study proved the positive impact of using bulletin boards on the writing process. Besides in comparison with before, a teacher could teach a lot through bulletin boards (Goodnouoh, 2002).

The result of this study supported positive effect of Instructional strategy (INS) and Environmental strategy (ENS) on young learner's grammar achievement. Young children can learn better throughout activities which they can find funny. EFL teachers should be aware of the grammar and structures and teach minimum of grammar (Scott \& Ytreberg, 1990). If teachers use grammar structures in their lessons as much as possible and provide EFL students more games and participation in class activities, they can notice and learn better the new language including its grammar (Povjakalova, 2012).

As it was proven before Instructional strategies have positive impact on student's achievement. The Mcrell study (2000) identified Instructional strategies which had impact on student's achievement. Twenty studies have proven the effectiveness of nine Instructional strategies some with the highest and some with the lowest effect. However, no Instructional strategies have equal effect in all situations. The effectiveness of Instructional strategies all depend on the skill and thoughtfulness which teacher applies to the strategy. Instructional strategies are the tools which EFL teachers should not be expected to work on equally in all the situations with all the students (Marzano \& Gaddy, 2000).

Moreover, ENS strategy can benefit EFL students if EFL teachers follow the essential instructions in creating the bulletin boards. In other words, EFL teachers should be aware of classifying the content from simple to difficult and highlight the most important issues. Besides, to make EFL students aware of the content revisit the board with EFL students and check the readability of the board (www.makinglearningvisible, 2005).

\section{References}

Bejarano, Y. (1987). A cooperative small-group methodology in the language classroom. Tesol Quarterly, $483-504$.

Ashurst, E. J., Jones, R. B., Williamson, G. R., Emmens, T., \& Perry, J. (2012). Collaborative learning about e-health for mental health professionals and service users in a structured anonymous online short course: pilot study. BMC medical education, 12(1), 37.

Burgess, J., \& Etherington, S. (2002). Focus on grammatical form: explicit or implicit?. System, 30(4), 433-458. Damra, H. M., \& Al Qudah, M. (2012). The effect of using native language on grammar achievement and attitudes toward learning of basic stages EFL students in Jordan. International Journal of Business and Social Science, 3(1)

Ellis, R. (1994). The study of second language acquisition. Oxford University Press.

Marzano, R. J. (1998). Rethinking Tests and Performance Tasks. School Administrator, 55(11), 10-12.

Marzano, R. J., Gaddy, B. B., \& Dean, C. (2000). What Works in Classroom Instruction.

Marzano, R. J. (2009). Setting the record straight on" high-yield" strategies. The Phi Delta Kappan, 91(1), 30-37.

Marzano, R. J., \& Haystead, M. (2009). Final report on the evaluation of the Promethean technology. Englewood, CO: Marzano Research Laboratory. Retrieved May, 25, 2010.

Monroe, M. C., Andrews, E., \& Biedenweg, K. (2008). A framework for environmental education strategies. Applied Environmental Education \& Communication, 6(3-4), 205-216.

Graham, A. (2013). Managing Airports 4th Edition: An International Perspective. Routledge.

Gray, B., Andrews, K., \& Schroeder, S. (2011). What are Alberta's K-12 Students Saying about Learning with Technologies?. Student Reactions to Learning with Technologies: Perceptions and Outcomes: Perceptions and Outcomes, 42.

Goodnough, A. (2002). Teachers Dig Deeper to Fill Gap in Supplies. New York Times, 21.

He, H. (2013). On FL Learners' Individual Differences in Grammar Learning and Their Grammatical Competence Training. Theory and Practice in Language Studies, 3(8), 1369-1374.

Hill, J. D., \& Miller, K. B. (2013). Classroom instruction that works with English language learners. ASCD.

Larsen-Freeman, D., \& Michael, H. Long.(1991). An introduction to second language acquisition research. Studies in Second Language Acquisition, 15, 394-395.

Leki, I. (1995). Coping strategies of ESL students in writing tasks across the curriculum. TESOL quarterly, 29(2), 235260.

Kumaravadivelu, B. (1991). Language-learning tasks: Teacher intention and learner interpretation. ELT journal, 45(2), 98-107.

Lucas, A. M. (1972). Environment and environmental education: conceptual issues and curriculum implications.

Nye, P. A., Crooks, T. J., Powley, M., \& Tripp, G. (1984). Student note-taking related to university examination performance. Higher Education, 13(1), 85-97.

Scott, W. A., \& Ytreberg, L. H. (1990). Teaching English to children. ^ eLondon London: Longman.

Parker, J. E., Heitzman, S. M., Fjerstad, A. M., Babbs, L. M., \& Cohen, A. D. (1995). Exploring the role of foreign language in immersion education. Second language acquisition theory and pedagogy, 235-253.

Povjakalová, A. (2012). Teaching Grammar to Young Learners using Interactive Whiteboard.

Wells, N., Free, M., \& Adams, R. (2007). Nursing research internship: enhancing evidence-based practice among staff nurses. Journal of Nursing Administration, 37(3), 135-143.

Wu, W. C. V., \& Wu, P. H. N. (2008). Creating and authentic EFL learning environment to enhance student motivation to study English. Asian EFL Journal, 10(4), 211-226. 


\section{Appendix}

Appendix A
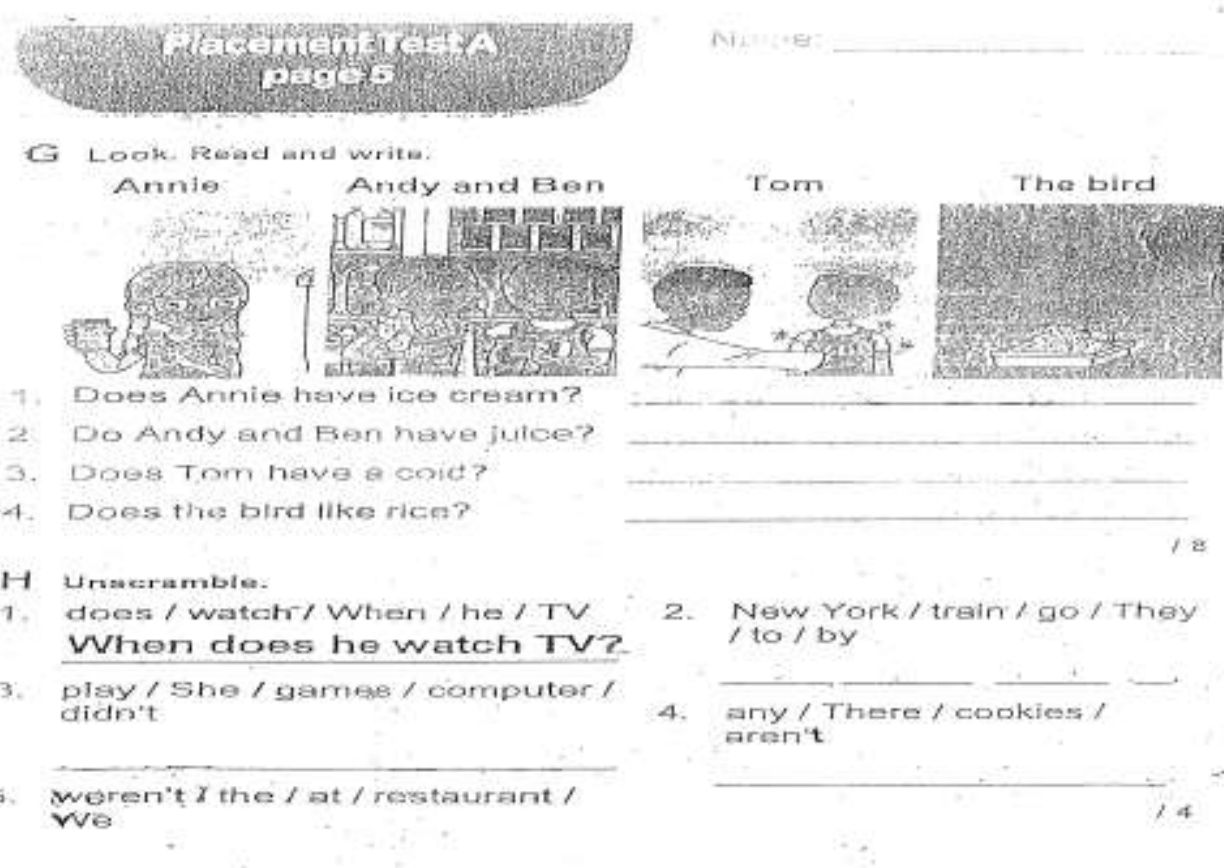

2. New York/train/go/They / to / by

4. any/There/cookies/
aran't

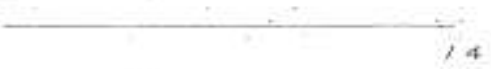

\section{Appendix A continued}

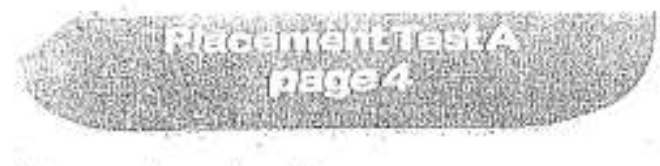

E Look and write.
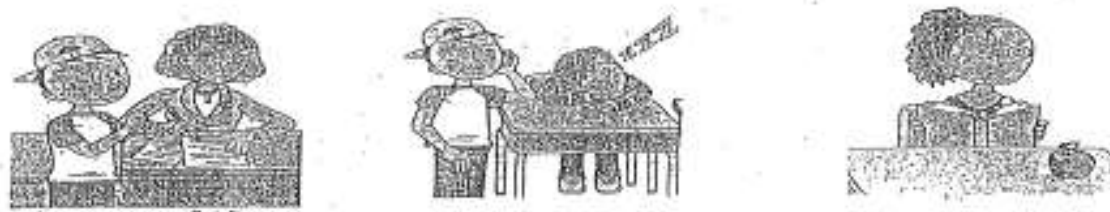

1. She's vvriting

2. He's

3. $1 \mathrm{~m}$

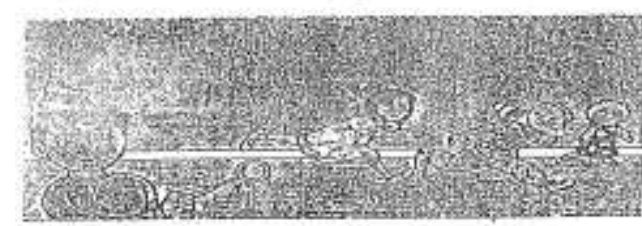

4. They're

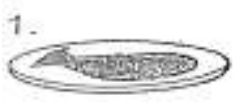

h 2 .

w

v

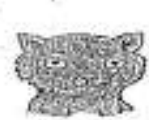

cat

$f$ ish

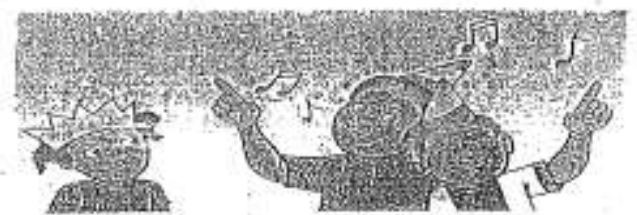

5. They're

/ $\mathrm{B}$ 


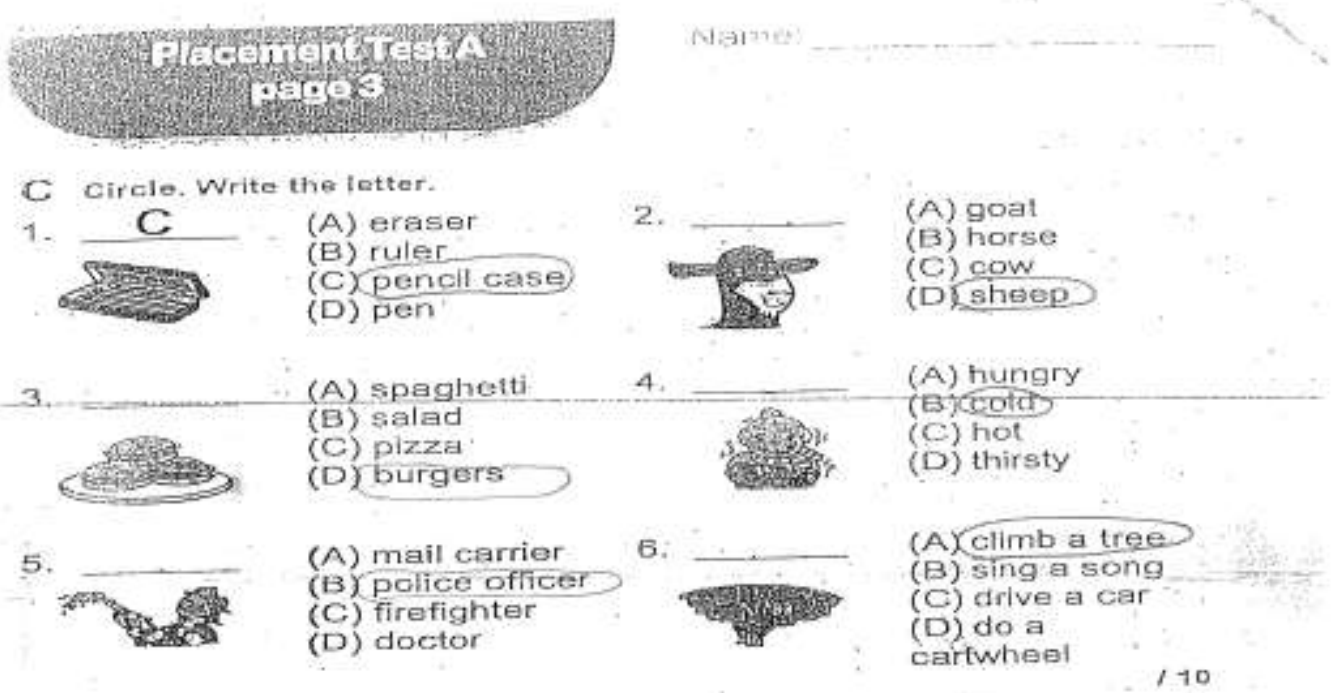

D Write.

oin what who's doing time

1. he? He's my brother.

2. What is it? $1 t^{\prime}$ s two thirty.

3. are those? They"re socks;

4. Where's the book? $1 t^{\prime}$ 's the stielf.

5. What are you ? I'sn studying English.

Appendix A continued

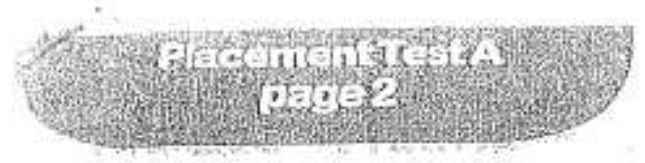

Namige: $S_{R} \backslash n x$

reading and Writing

A Write the letters.

\begin{tabular}{|c|c|c|c|c|c|c|}
\hline $\mathrm{Aa}$ & $\mathrm{Bb}$ & $\mathrm{Cc}$ & - Dd. & Ee & & \\
\hline Ef & $\mathrm{Gg}$ & Hh & ii & $\sqrt{d}$ & & \\
\hline Kk & LI & $M \mathrm{~m}$ & $N D$ & OO & & \\
\hline$P P$ & $Q q$ & $\mathrm{Rr}$ & Ss & $1 \pm$ & & \\
\hline Uப & Vv & Ww & $X x$ & $Y$ & . & $\begin{array}{l}\mathrm{Zz} \\
110\end{array}$ \\
\hline
\end{tabular}

B Read and match.

1 It's a butterfly.

2. This is rice,

3. I'm a boy.

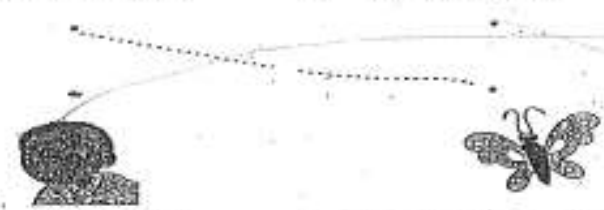

4. Is she thirsty?

5. -1 can ride a bike.
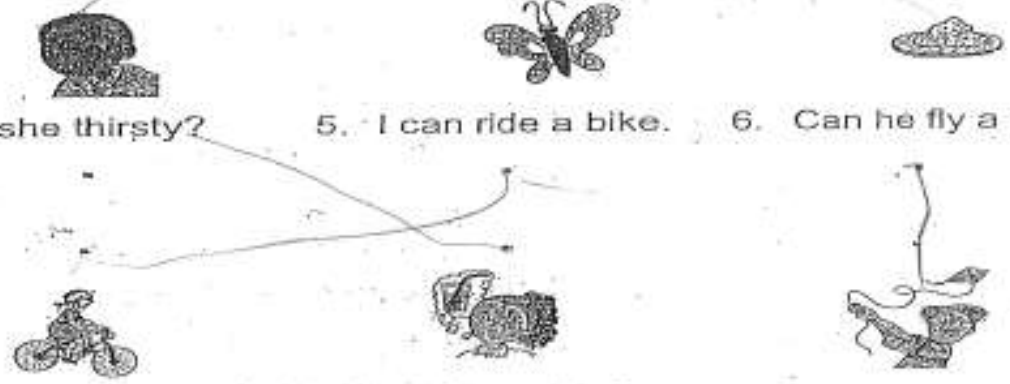

6. Can he fly a kite?

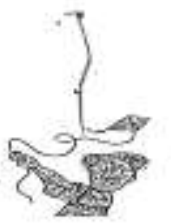


Appendix B

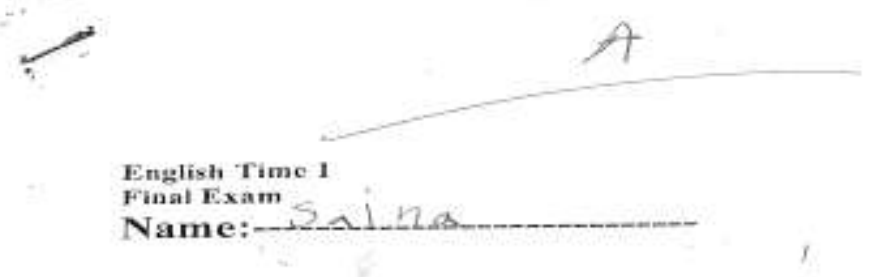

5DITIDTI

Final Exam

A. Look read and completes the conversations:

(5)

$$
\text { Bless-Thanks }
$$

1. Ab-choo!

Bets

Think, rak:

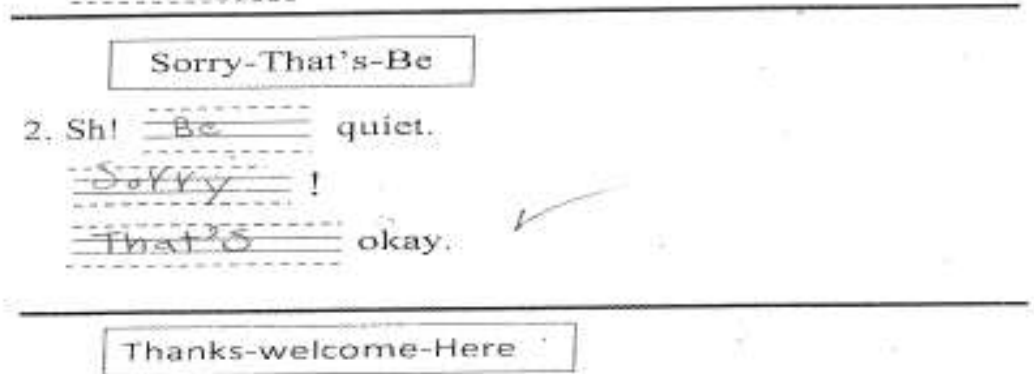

3. Itete you are.

Thanks

You're

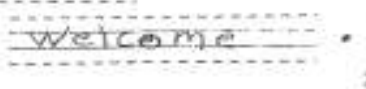

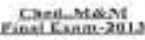

Appendix B continued

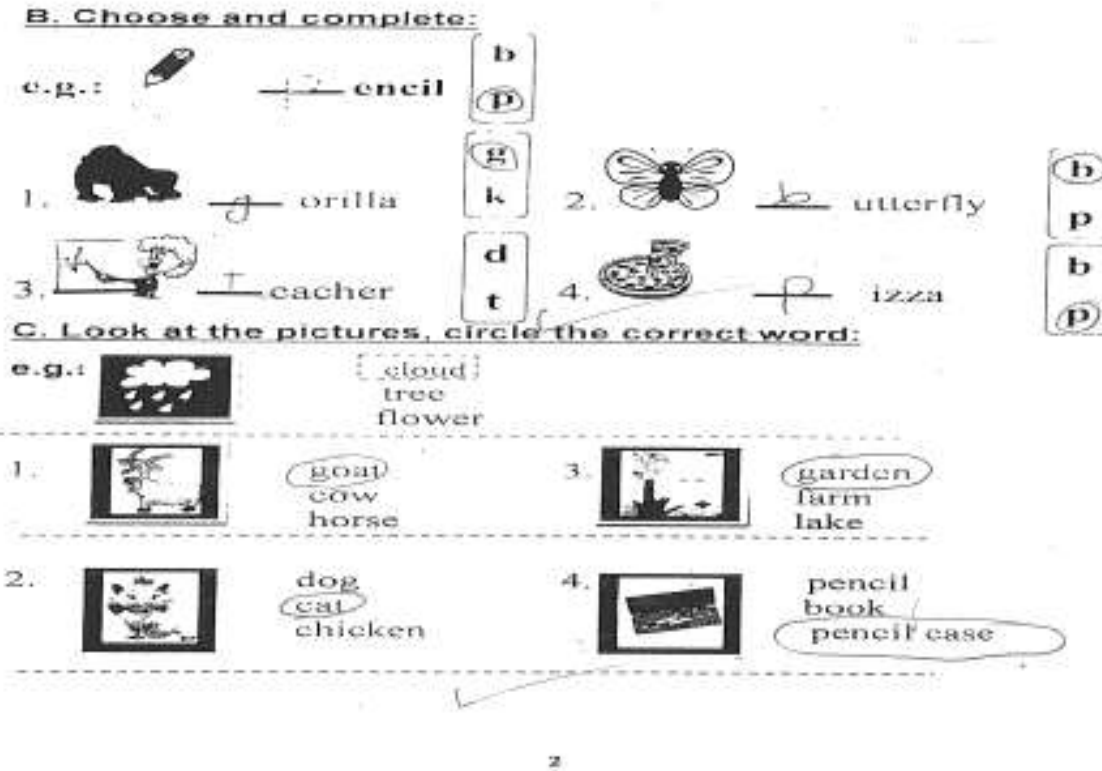


Appendix B continued

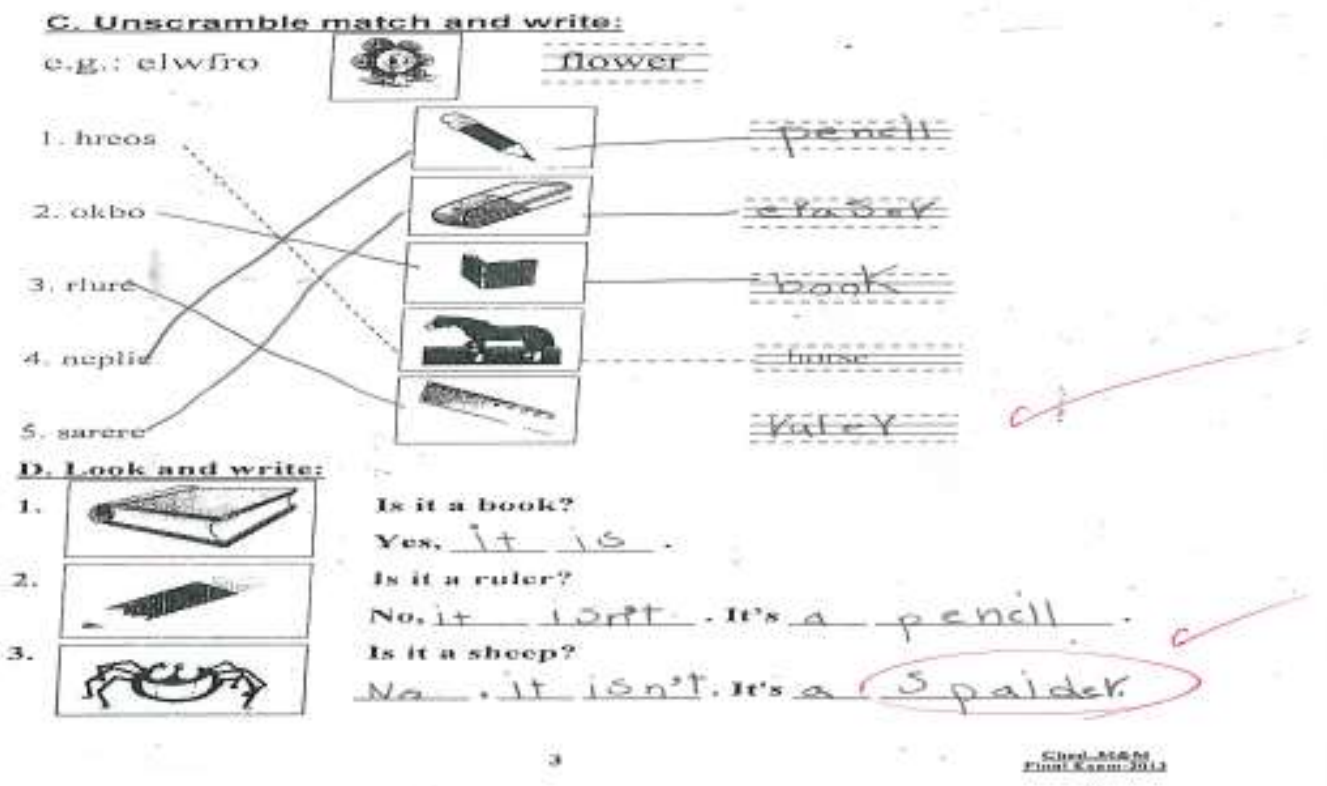

Appendix B continued

D. Leok and write:

a 20

1.

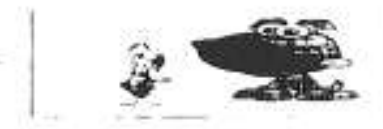

2.

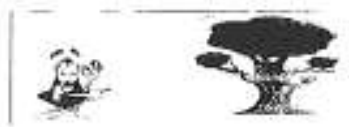

3.

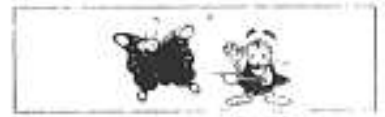

4.

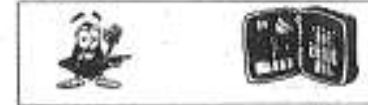

vinats this?

It's a cloud.

$$
\text { whates this ? }
$$$$
\text { Itsedsg. }
$$

whatis that $X P$

Ifosatyee.

What?S.tbis 5.

It>sex butterfiy.

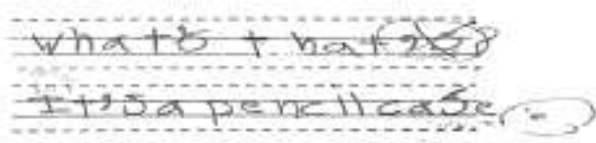

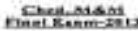




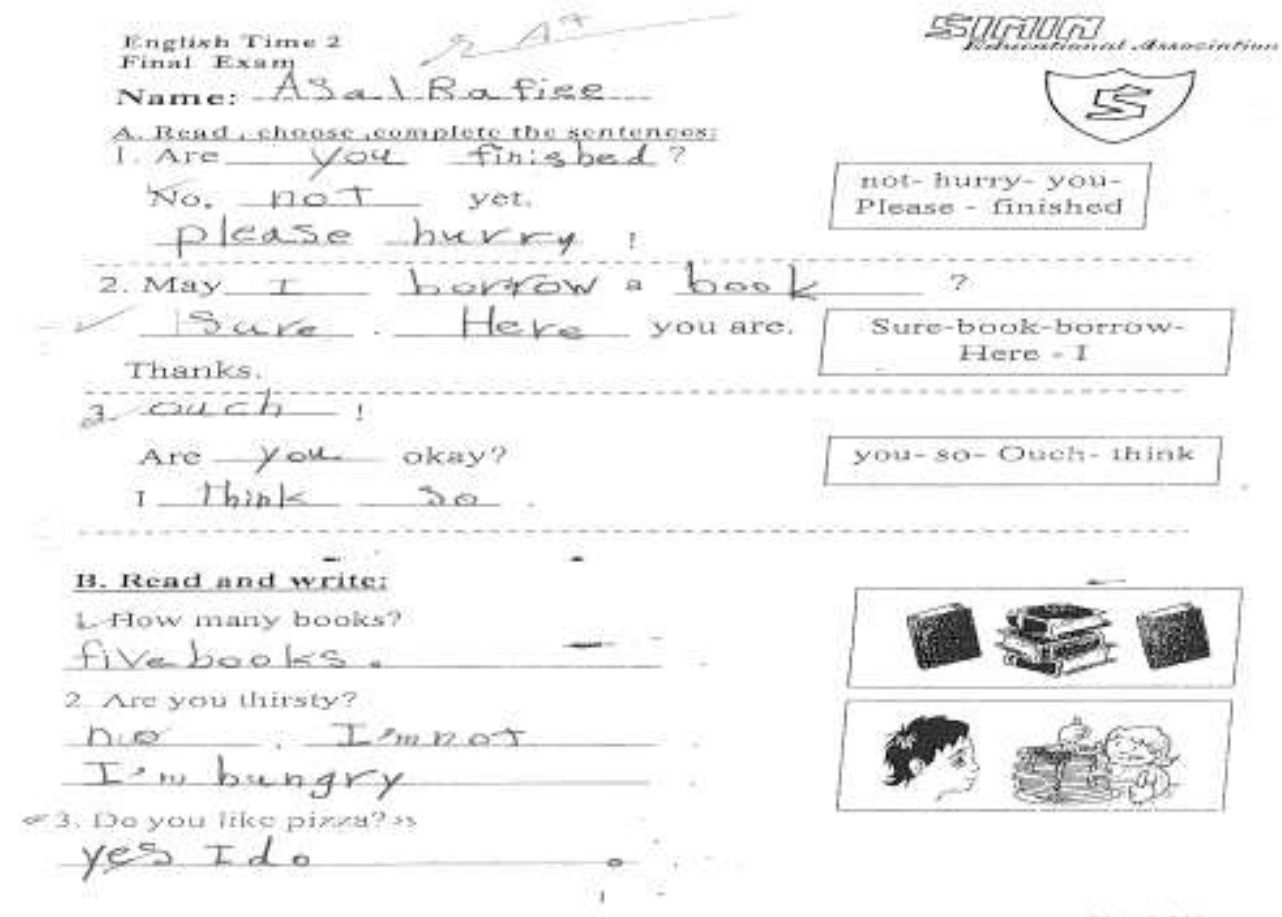

Appendix C continued

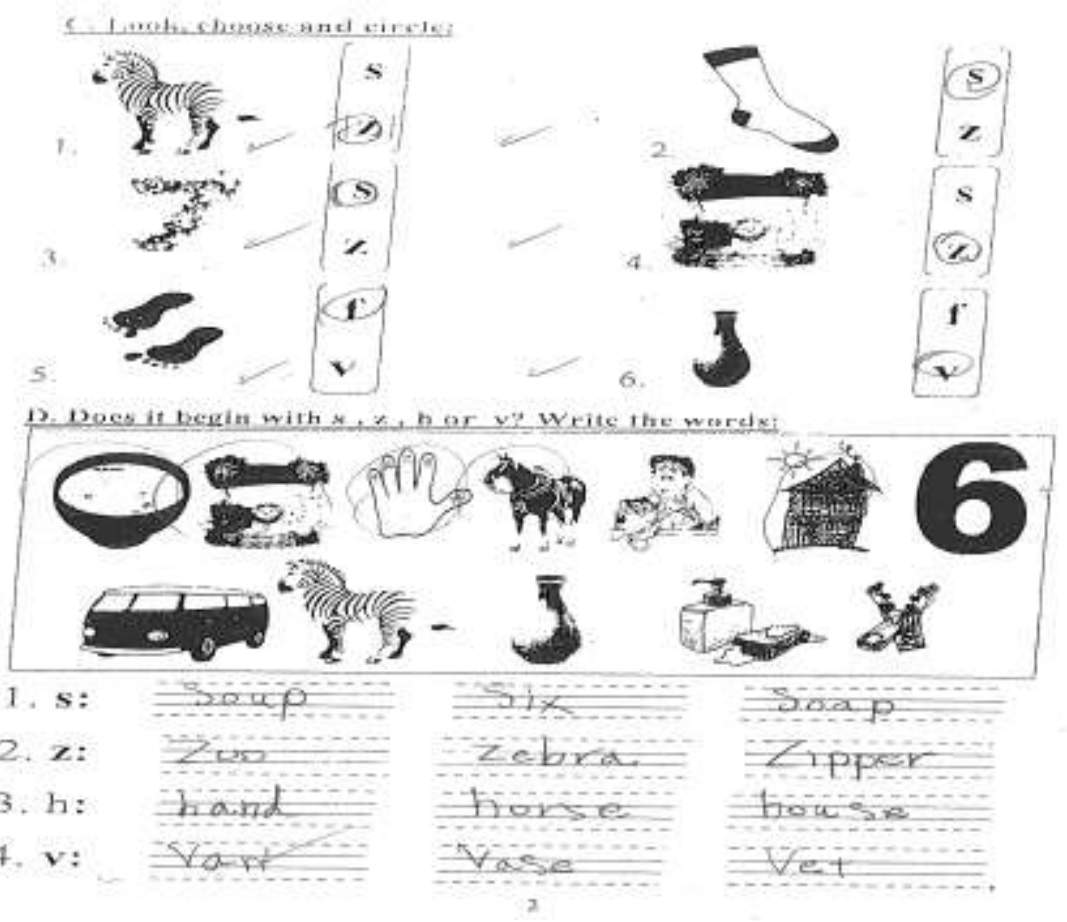




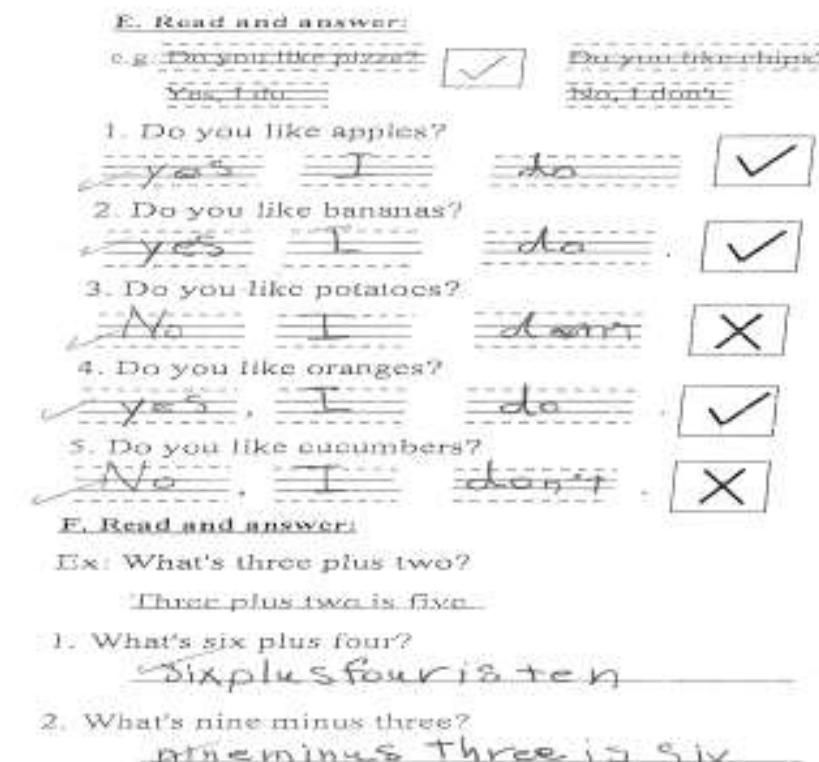

Appendix D

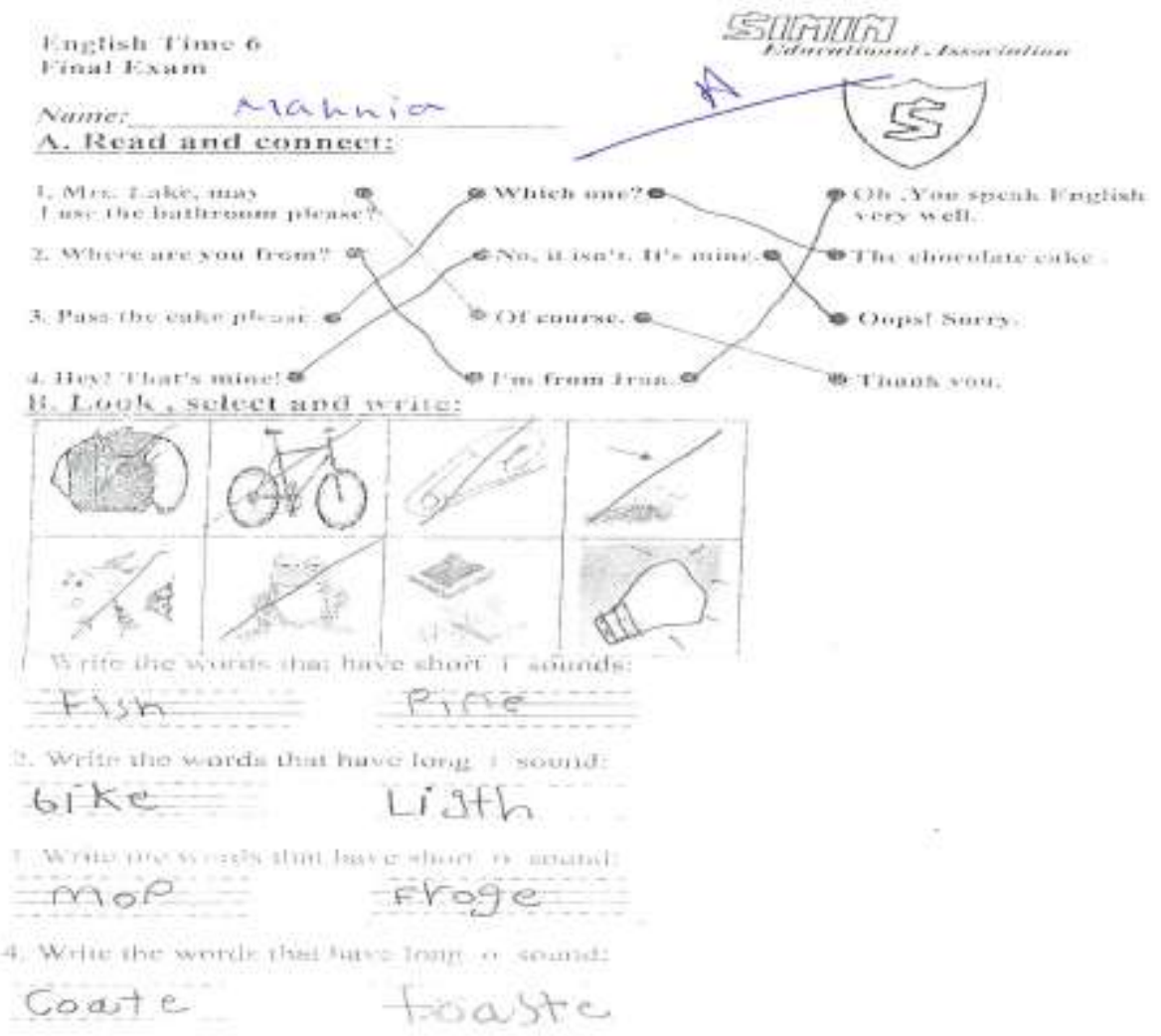




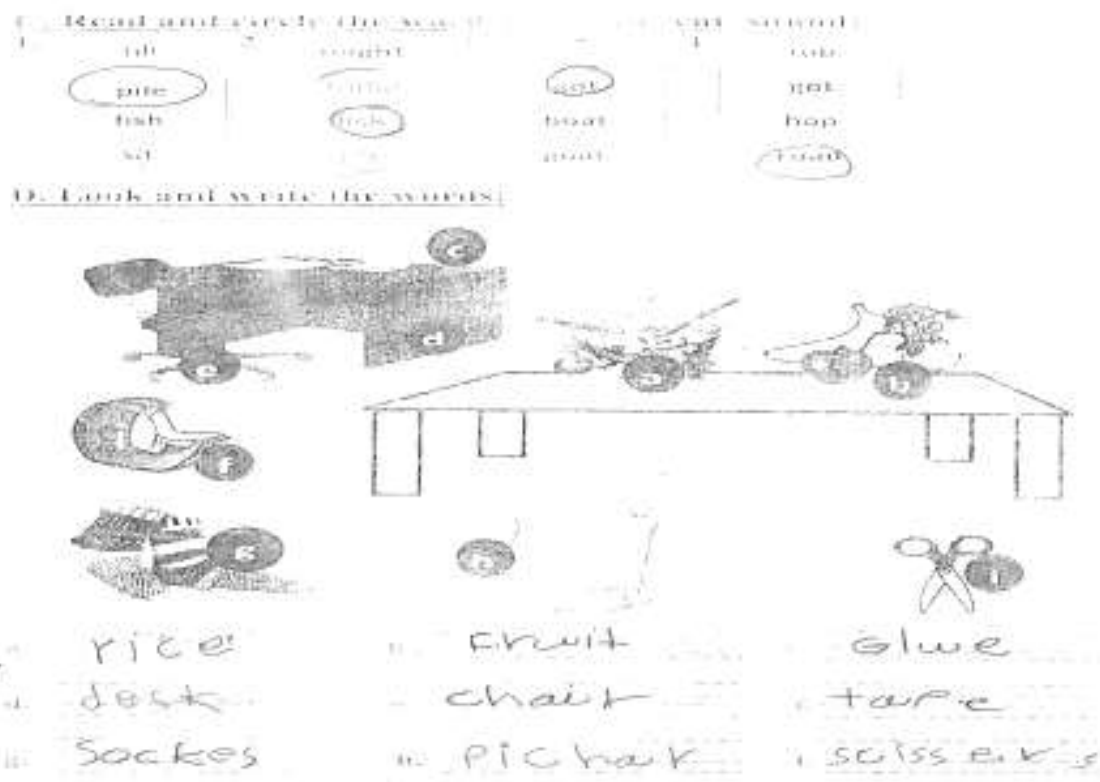

\section{Appendix D continued}

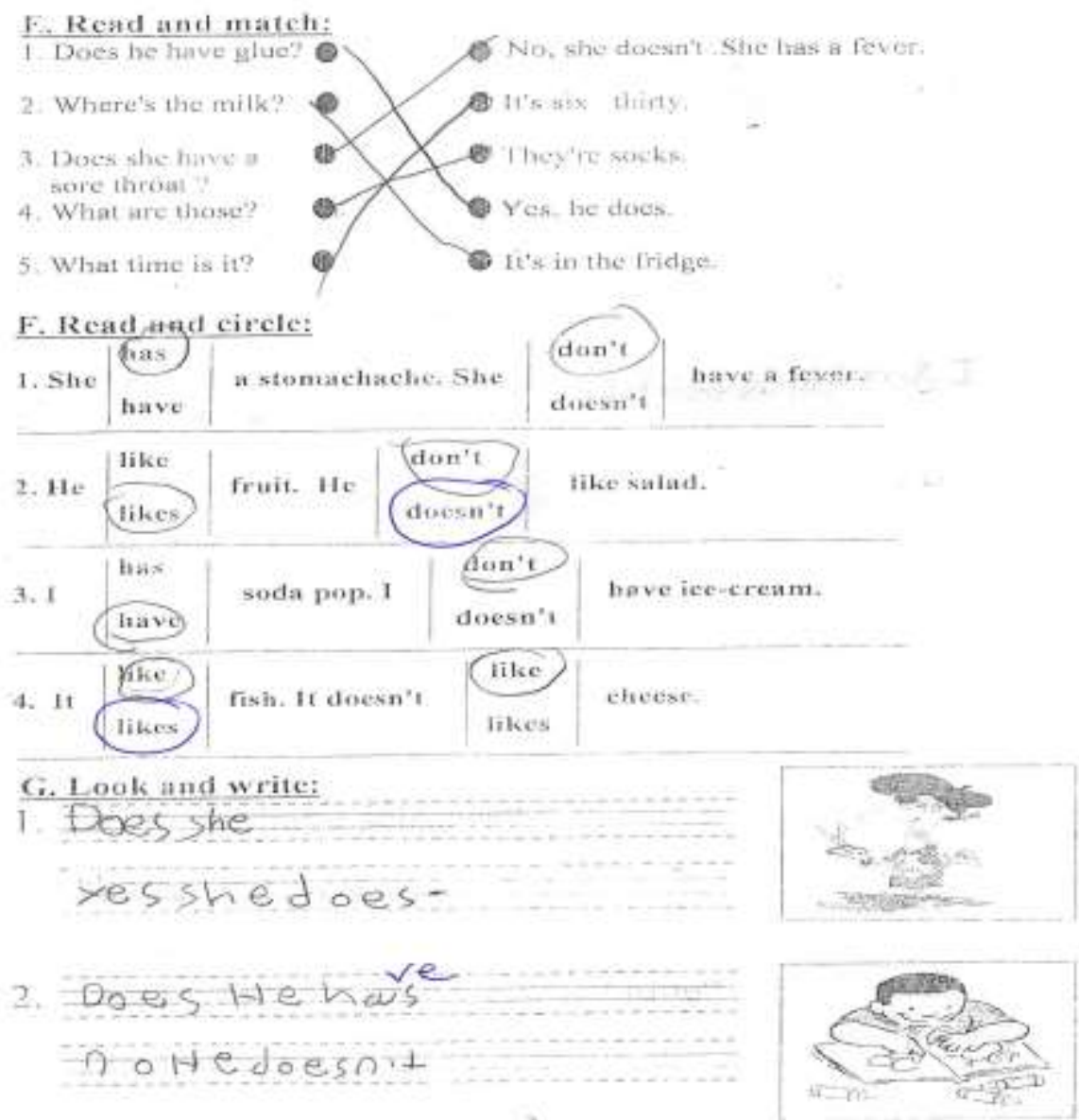




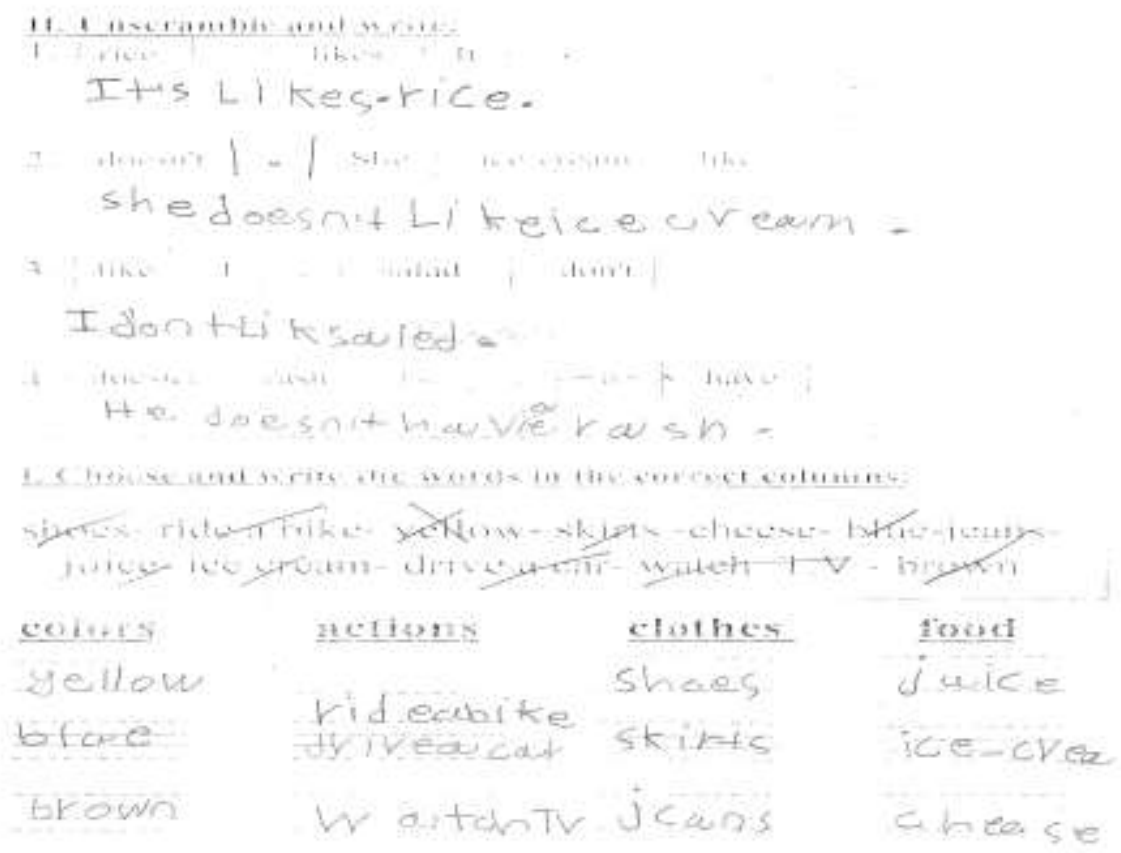

Appendix D continued

TRend and answer:

I-Does she have म circle?

Doshedoesnt.

2-Is this a square?

Doitdoesnit.

What shape is it?

It's terow you atel

K. Read and toming

eleary up- shatre-palitetatke turns theip

Are you s mico porgon?

1 i-cleancup

2. Hele

* mogther in the kitenco

3. $x$ t-euketewking in preying bianes

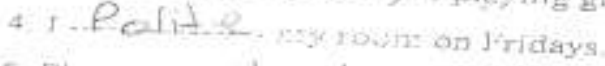

5 Please, be 5 hew the and knock at the door

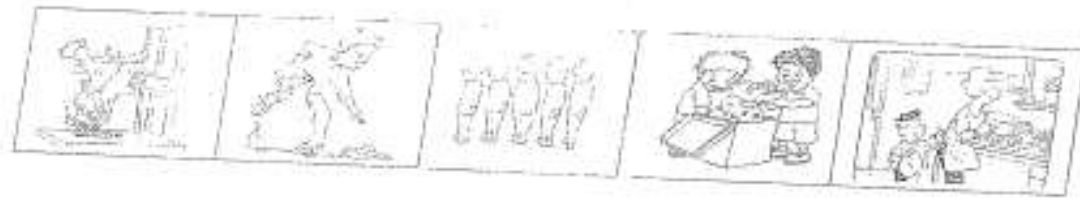

s.

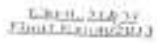

